\title{
The Analysis of Current Variation on the Electrical Energy Measurement
}

\author{
Guan Ling, Liu Min, Zhang Xiaoshu, Xie Xinnan, Xu Mei, Wang Lei, Wang Xue, \\ Jin Jing, Cao Huiyan, Zhu Ying, Zhao Xinhua, Zhao Chang \\ Fushun Power Supply Company, Liaoning Electric Power Company Limited, State Grid, China
}

fushunpowersupply@163.com

Keywords: current variation; electrical energy metering; watt-hour meter; power factor

\begin{abstract}
As a special commodity, electricity has the characteristics of the being produced and used at the same time and it is not physical visible. In order to avoid the loss in circulation of electricity, we should have a thorough understanding and accurate recognition of "power". The watt-hour meter measuring power depends on the product of voltage, current, power factor and the time. Changing any of these elements will have an impact on the measurement of electrical energy which will cause the measuring error of electrical energy and also cause the economic loss to power supply enterprise. Through the description of the working principle of the watt-hour meter, this thesis expounds the current and the current changes can impact to electrical energy measurement.
\end{abstract}

\section{Introduction}

With the rapid development of national economy the living standard of people is increasing day by day, and the power demand and power consumption of is increasing at the same time. Power supply enterprises statistics all enterprises and institutions' production through the country, office and ordinary people by means of electric energy metering to know how much power they need for daily life, so as to measure the country's economic development level, so that they can ensure the electric power safely and supply stably of the whole harmonious society. In accuracy of electric energy metering will affect national economic development and social stability. Under the drive of "money", stealing power will reduce the spending of firms and households, which directly results that the legal rights of power supply are harmed and the huge loss of state-owned assets.

When talking about "electricity", we will think of current and voltage. Because they are the most direct factors for electricity, which are also the electrical terms that the ordinary people come into contact with the most. The followings mainly discuss the impact of current changes on electric energy metering.

\section{The concept of the current}

The directional movement of charge in the circuit is called current. The amount of charge passing through the cross section of the conductor per unit time is called the current strength, which is also called current for short. The unit of electric current is "ampere", represented by the symbol "I"[1].

The electricity we used in daily life is alternating current (ac). Alternating current (ac), refers to the size and direction of a kind of current intercropping cyclical changes from time to time. The most basic form of the current is sinusoidal current which has a wave-shape change. As shown in Figure 1.

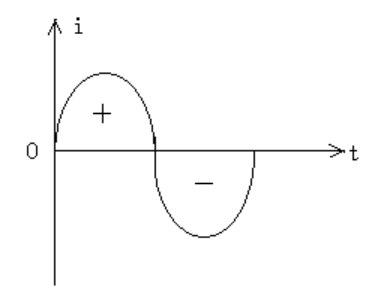

Fig.1 Sinusoidal Current 


\section{The concept of energy metering}

The measurement appliance that used by electricity customers to record how much electrical energy they used is known as the electric metering device. It is the "balance beam" that used by power supply enterprises and electric power customers to settle the electricity measurement. Watt-hour meter is the electric energy metering device we contact the most in daily life, which is the measuring tool to count the power the enterprises used. Watt-hour meter is mainly used for electric energy metering, which measures electricity. It's the work done by current. Power unit is "kWh," with that symbol "kWh", commonly known as the "degree"[2, 3].

\section{The working principle of watt-hour meter}

(1)The working principle of single phase induction watt-hour meter

The operating principle of inductive watt-hour meter is that the electromagnetic force will be generated by the interaction of the eddy current caused by the voltage and current coils on the aluminum plate and the alternating flux, and the force will rotate the aluminum plate. The braking torque will be introduced to make the rotate speed of the plate directly proportion to the load power, then the computer can calculate the number of revolutions of the plate by means of the transmission of the axial direction gear to measure electric energy[4]. The main components of the inductive watt-hour meter includes voltage coil, current coil, rotating plate, axis of rotating, braking magnet, gears and register. According to the working principle, we can change the measurement of electric energy by changing the input current, voltage, phase, rotating speed and gear-ratio. The single phase watt hour meter is shown in Figure 2.

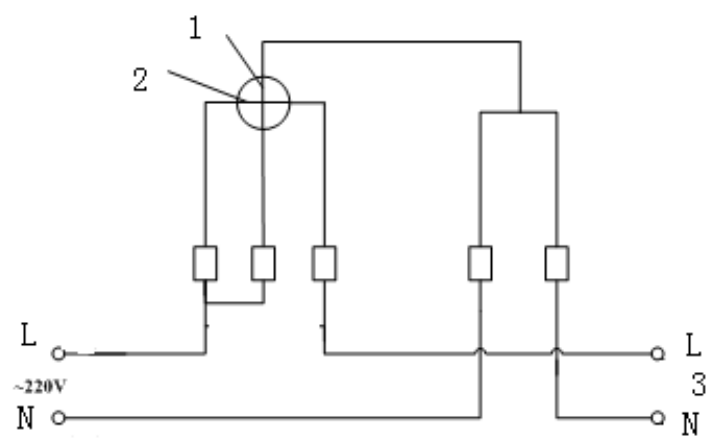

Fig.2 Wiring diagram of single phase watt hour meter

Note: 1.Votage coil; 2. Current coil; 3. Load; L: Firing line; N: Null line

(2) Working principle of single-phase intelligent electronic watt-hour meter

As the times progress and unceasingly increase in the science and technology, the watt-hour meter is also in unceasing renewal. It has updated from the traditional inductive type to intelligent electronic type which consists of electron component. The working principle can be describe as followed: first, it samples transient signal of voltage and current from customers, then the signal will be processed by the specialized integrated circuit and converted into the output pulse which is positive proportional to the electric energy. At last the pulse signal will be transformed into electricity consumption after the processing and control of the single chip microcomputer. The variation of the current can also affects the measurement of the electricity consumption [5].

(3) The working principle of the watt-hour meter in three-phase four-wire system

The working principle of three-phase four-wire watt-hour meter is nearly the same as the one of single-phase; it can be used to measure the active energy in the three-phase four-wire system with symmetrical or asymmetrical load. This meter can be regarded as the combination of three single-phase watt-hour meters, and it is equipped with three set of current and voltage components. Two co-axial rotating aluminum plates are plated on the upside and downside, and the upper aluminum plate is equipped with two sets of drive elements and a set of register. The iron core is separated type. The voltage component is semi-closed inserted. In working condition, three sets of current and voltage components of the meter generate a shifting magnetic field, and the total torque on the aluminum plate is the sum of the torque. The rotating speed of the aluminum in the magnetic 
field is positive proportional to the active power of the load so as to measure the electric energy. It is not hard to see that the variation of the current in any component will affect the measurement of electric energy. The three-phase four-line watt-hour meter is shown in Figure 3.

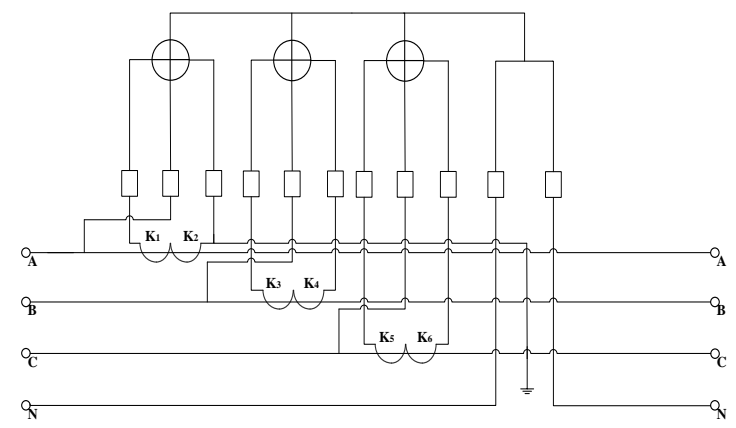

Fig. 3 The wiring diagram of three-phase four-line watt-hour meter

Thus, the working principle of single-phase inductive type watt-hour meter, new type single-phase electronic type watt-hour meter and three-phase four-line active power watt-hour meter are all related to the current flowing through the meter. The current flowing through the meter is the decisive factor which can affect the measurement of electric energy.

\section{The working principle of current transformer}

As we mentioned the watt-hour meter in three-phase four-line system above, we have to introduce the current transformer which is in series with the watt-hour meter. The wiring diagram of current transformer is shown in Figure 4.

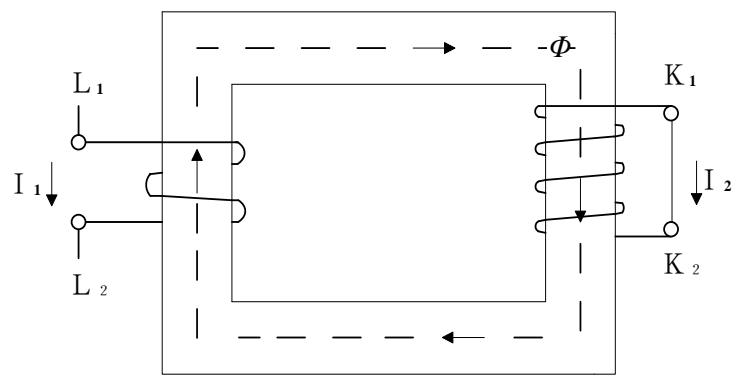

Fig. 4 The wiring diagram of current transformer

Current transformer is made according to the principle of electromagnetic induction. Current transformer is made up of closed iron cores and windings. There are fewer windings on the primary side than that on the secondary side, and the windings of primary side are in series with the circuit which current we need to be measured. Thus, the primary side windings always carry all the current of the circuit. The windings of secondary side are often in series with the measuring instruments and projective circuit, and the secondary circuit is always closed during the operation of the current transformer. The windings in the protective circuit of the measurement instrument have a very small resistance, and we can consider that the current transformer works in the condition of short circuit. Current transformer can convert the large current of the primary side into the low current of the secondary to measure the current with a closed secondary circuit.

\section{The relation between current and electric energy measurement}

We can elaborate more about the calculation of electric energy since we already have a basic understanding of the constituent elements which are related to watt-hour meter. As we mentioned above, watt-hour meter is the measuring instrument of electric energy, and it measures the electric energy which is the work done by current.

It is obvious from the formula that it is the value of current, voltage, and power factor that influence the electric energy, so the result of the measured value will be affected if we change the value of current passing through the meter. 


\section{The method to change the current passing through the watt-hour meter}

(1) Shorting the current circuit

1) Changing the number of coils of current in the measuring equipment

Current coils and the parallel resistance form a parallel circuit when the parallel resistance is smaller than the current coils. According to the divided flow theory of parallel circuit, the current passing through the branch circuit is negative proportional to the branch resistance which means that most current will flow through the parallel resistance (branch circuit with a small resistance). A small fraction of current will pass through the current coils of the watt-meter. This will proportionally reduce the rotate speed of the watt-hour meter and affect the measured result. According to the calculation formula, the work done by the current will be reduced when the current lessened and the measured value of electric energy will be reduced.

2) The current coils of short circuit measurement instrument

The current coil is normally shorted from the outside or inside of the watt-hour meter. The frequently used method is that inserting wires or parallel resistance into the phase-line input terminal and output terminal which will get a shunting effect as shown in Figure 5.

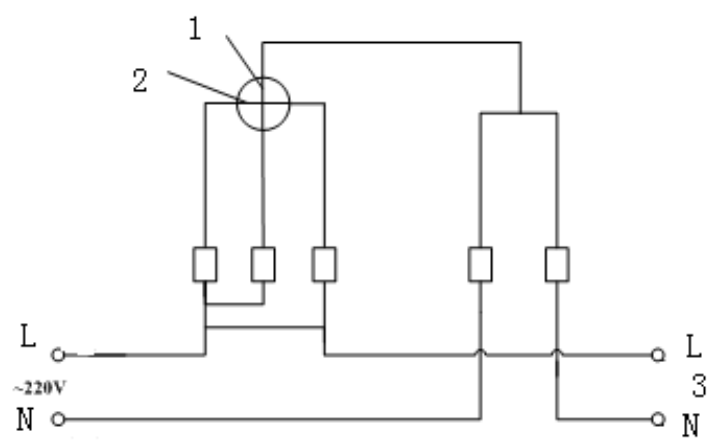

Fig. 5 Schematic diagram of shorted current coil

Note: 1. Voltage coil; 2. Current coil; 3. Load; L: firing line; N: null line

Most of the current will flow through the shorted wire because its resistance is nearly zero and there is barely no current in the current coil of watt-hour meter. Thus, the watt-hour mete will not continue to rotate and the electrical power consumption can not be measured.

3) The primary coils of shorted current transformer

According to the working principle of current transformer, as it is shown in figure 4 that the current of primary side will be quite small when its primary side is shorted, and the current of secondary side will become smaller. The current passing through the watt-hour meter will be reduced because the current first pass through the current transformer then the watt-hour meter. Thus, the measured result will not be correct and less electrical energy will be measured.

4) Shorted terminal of current transformer

The load current passing through the current coil will be diverted once the terminals of the current transformer are shorted by wires, and the current will not flow through the watt-hour meter which will cause an inaccurate result of the meter.

(2)Adjusting the firing and null line

According to the side structure of watt-hour meter, if we first adjust the firing and null line of the incoming line terminal of watt-hour meter then the incoming and outgoing terminal of the null line should be shorted by metal connection. Thus, we can use the self-designed null line when we use electrical energy, and the watt-hour meter will stop working as these is no reverse current flowing through the current coil. This method can be implemented only if we install the control switch in room, and the null and firing line connected with the watt-hour meter can be adjustable. The switch can be on and off at any moment, and the current can be controlled to pass through the current coil or not. Through this way the measurement of electrical energy can be manipulated, but in real life this will threat to the electricity safety.

(3)Use electrical power of a bypassing measurement instrument connection mode

This way of changing the current is mainly used when private wires are connected to the public 
lines which mean that there is no current passing through watt-hour meter because the incoming terminal of electric wire is located ahead of the meter. Based on the measuring formula $\mathrm{W}=\mathrm{UI} \cos \Phi \mathrm{t}$, we can see that if $\mathrm{I}=0(\mathrm{~W}=0)$ the watt-hour meter will stop working. However, the large contact resistance and the low quality of insulation and sealing will cause the flashover even the break of the wire deal to the thermal effect of current. This will cause serious threat to the safe operation of electric power line.

\section{Summary}

In conclusion, many ways can change the current which affect the measurement of the electric consumption. This will not only cause a great economic loss of power supply enterprise but also the inaccuracy of the practical consumption of electrical energy. The accurate and effective reliability data is the key factor based on which the power supply enterprise can calculate power generation, power supply, power consumption and line loss, it is also an indicator of the state of the power supply enterprise. Only by improving the supervision of the market, raising awareness of electric power, improving educational level, professional quality and skill, and raising electric scientific and technology level can we avoid the above situation occurs, and only through this we can make sure that we can get an accurate measured result of the watt-hour meter. All of this is what we should try to achieve and create to build a good environment for power supply.

\section{References}

[1] Lan Yonglin, Tang Hong. The People's Republic of China national metrological verification procedures JJG 307-2006. General administration of quality supervision and quarantine. 2006

[2] Ma Ruisong, Shen Xiaodong. The People's Republic of China national metrological verification procedures JJG 597-2005. General administration of quality supervision and quarantine. 2006

[3] Liu Zhihai. Bar Code Technology and Program Design. Tsinghua University Press, 2009

[4] Zheng Yao. Electricity metering technical manuals. China Electric Power Press. 2002

[5] ST9020V3 Single phase watt-hour meter verification equipment user manual. Henan star hi-tech co., LTD. 2006 